\title{
Investigating the urban archaeological sites using Ground Penetrating Radar. The cases of Palatino Hill and St John Lateran Basilica (Roma, Italy)
}

\author{
Salvatore Piro and Daniela Zamuner \\ Istituto per le Tecnologie Applicate ai Beni Culturali, ITABC - CNR, Rome, Italy
}

\begin{abstract}
The geophysical prospection is generally considered as the attempt to locate structures of archaeological interest buried in the natural subsoil, but in many cases, when applied in urban centers, this attempt could fail due to the effect and disturbances caused by recent man-made structures in the subsoil, covering any signal related to possible archaeological structures. In the present paper the GPR surveys carried out in two urban archaeological sites in Roma, characterised by different targets and environmental conditions, are presented and discussed. The first site, a portion of Palatine Hill (archaeological center area of Roma) is characterized by natural soil on the surface and an overlapping of many archaeological structures in its volume. The second site, St. John Lateran Basilica (Roma), is characterized by artificial medium as road pavement, outside the basilica, and ancient buildings, below the actual basilica. The paper illustrates the two GPR surveys and the obtained results.
\end{abstract}

Section: RESEARCH PAPER

Keywords: GPR; urban area; Palatine Hill Roma; St. John Lateran Basilica Roma

Citation: Salvatore Piro, Daniela Zamuner, Investigating the urban archaeological sites using Ground Penetrating Radar. The cases of Palatino Hill and St John Lateran Basilica (Roma, Italy), Acta IMEKO, vol. 5, no. 2, article 11, September 2016, identifier: IMEKO-ACTA-05 (2016)-02-11

Section Editors: Sabrina Grassini, Politecnico di Torino, Italy; Alfonso Santoriello, Università di Salerno, Italy

Received: March 2, 2016; In final form May 23, 2016; Published September 2016

Copyright: : (C) 2016 IMEKO. This is an open-access article distributed under the terms of the Creative Commons Attribution 3.0 License, which permits unrestricted use, distribution, and reproduction in any medium, provided the original author and source are credited

Funding: This work was supported by PRIN 2012 national project $\mathrm{n}$. NFYHH2, for the Palatine site and by the Newcastle University (UK), for St. John Lateran Basilica

Corresponding author: Salvatore Piro, e-mail: salvatore.piro@itabc.cnr.it

\section{INTRODUCTION}

There are many important research and technical issues related to the investigation in urban areas to locate subsurface cavities and/or archaeological remains, to produce hazard mapping, that is of the highest priority, and archaeological risk maps. This is especially so in civil engineering where it is of key importance for managing safe urban and civil constructions. In many cases, cavities, such as subsidence features, voids and collapses represent disruptions to the geometry of an originally near-horizontal layered system. Geophysical techniques can be used to identify the feature geometries by contrasts in the physical properties, but can be greatly impeded by cultural features that interfere with instrument measurements (utilities, structures, surficial debris).
Site preparation can facilitate the field work and can improve the accuracy of the geophysical surveys and interpretations. The most useful site preparations are performance of a topographic survey to create a site grid, placement of location markers and removal of surficial debris and obstructive vegetation. Conditions of the geophysical field project that are subjected to site-specific design include: selection of appropriate techniques, instruments, accessories and settings; performance of dualtechnique surveys for redundant site coverage; performance of follow-up surveys and selection of instrument measurement density.

The critical phase of the geophysical survey in an urban area is the interpretation of the collected data and the characterization of the degree of confidence in the interpretations. 
The urban subsoil consists often of many layers documenting the history of a place, keeping records of alternating phases of construction and destruction. The shallow subsurface of modern cities contains reams of pipes, cellars, wells, cavities, tunnels, graves and foundation walls of former houses, churches and town fortifications. Underneath the tarmac of city roads and the paving stones of town squares layers of sand and gravel are criss-crossed with modern fibre optic and telephone cables and century old sewer pipes mixed with the debris of brick buildings.

The geophysical prospection of urban centres, which have been abandoned in the past and today are located under barren land, pose different methodological possibilities and challenges compared to surveys conducted in modern city centres.

While the first sites may successfully be prospected employing aerial photography, magnetometry, ground penetrating radar, earth resistance and inductive electromagnetic methods [1], many of these methods are difficult or impossible to use in the urban centre.

The most promising non-destructive geophysical prospection method for use in urban centres is GPR (ground penetrating radar). GPR measurements are less affected by the presence of metallic structures compared to magnetometer prospection and they result in the largest amount of data of all commonly employed near-surface geophysical methods, providing detailed three-dimensional information about the subsurface [2]. The Ground Penetrating Radar is an electromagnetic impulsive method much suited for shallow depth investigations, as it can supply subsurface profiles grouped in vertical radar sections. The transmitter-receiver antenna is pulled along the surface of a site, signals are sent with a highly directive radiation pattern into the ground and echoes are returned from targets in the ground within a few meters. The emitted radar signal is a pulse of electromagnetic radiation with nominal frequency value in the range 15 to 2500 $\mathrm{MHz}$. The velocity of an electromagnetic wave in air is 30 $\mathrm{cm} / \mathrm{ns}$. In soils the velocity is less, as typical values are in the range 5 to $15 \mathrm{~cm} / \mathrm{ns}$ [2].

While geophysical prospection is generally considered as the attempt to locate structures of archaeological interest, in many cases, when applied in urban centres, this attempt could fail due to the effect and disturbances caused by recent man-made structures in the subsoil, covering any signal related to structures of archaeological interest. Modern underground structures (as bars and slabs of reinforced concrete, metallic pipes, cables and associated trenches and building debris) occurring at shallow depth often display a stronger contrast in physical properties relative to the surrounding subsoil than less well expressed archaeological structures, which often are buried at greater depth.

Challenges for GPR prospection in city centres lie in the large number of obstacles present in the urban environments. Traffic islands, metallic gully covers, lamp posts, buildings, trees and parked vehicles cause irregular survey geometries, holes in the surveyed area and disturbing anomalies in the GPR measurements.

In Section 2 the GPR surveys, carried out in two urban archaeological sites characterised by different environmental conditions, are presented and discussed.

\section{ARCHAEOLOGICAL PROSPECTION IN URBAN CENTRES}

As indicated in the previous section, the archaeological geophysical prospection in the urban area can be limited or affected by recent man-made structures in the sub-soil. In the present paper the surveys made with geophysical methods to investigate two different sites are presented and discussed. The first site, a portion of Palatine Hill (archaeological centre area of Roma) is characterized by natural soil on the surface and an overlapping of many archaeological structures in its volume. The second site, St. John Lateran Basilica (Roma), is characterized by artificial medium as road pavement, outside the basilica, and ancient buildings, below the actual basilica. To investigate these two sites the GPR (Ground Penetrating Radar) system equipped with different antennas (frequencies) and with specific instrumental configurations have been employed.

\subsection{Palatino Hill}

To enhance the knowledge of the subsoil between the N-E foot of Palatino Hill and Coliseum Valley (Rome) as to the location and conservation of unknown buried Roman structures, a scientific collaboration between the Sapienza University at Roma (Department of Archaeology) and the Institute of Technologies Applied to Cultural Heritage (ITABCCNR), was initiated in 2001 and it is still in progress. The study area is characterised by a sequence of complex buildings, related to the Roman period between the late Republican and Severo's age (200 AD). A thick section of alternating sedimentary and volcanic deposits constitute the framework of the Palatine, and locally crops out along the north-western slope of the hill.

In this complex site a series of GPR surveys employing different frequencies were carried out. For the field measurements two different GPR SIR Systems (GSSI), one equipped with a 400 and $500 \mathrm{MHz}$ antenna (high-frequency) with constant off-set and the other employing a $70 \mathrm{MHz}$ monostatic antenna (low-frequency), were used. The 400 and $500 \mathrm{MHz}$ antenna were as a compromise between depth penetration to about 2 to 3 meter and resolution of features on the order of 0.15 to $0.20 \mathrm{~m}$ in order to define the archaeological features of interest. The $70 \mathrm{MHz}$ antenna was employed to investigate at a depth penetration more than 2 to $3 \mathrm{~m}$ and with a resolution more than $0.30 \mathrm{~m}$, comparable with the dimensions of the expected archaeological foundation structures.

Acquisition was made using a high-resolution approach in which parallel profiles were recorded very closely across the site. Signal processing, image processing, and visualization techniques have been used in conjunction with data modelling, elaboration, and interpretation of the recorded subsurface amplitudes [3].

GPR surveys were performed, during September 2001, November 2002, September 2003, May 2004, January 2008 and February 2011 using a 400 and $500 \mathrm{MHz}$ (GSSI) bistatic antenna with constant offset, at selected areas on the N-E foot of Palatino Hill and in the Coliseum valley. GPR surveys were also performed during November 2002, 2003 and February 2008 with a $70 \mathrm{MHz}$ (Subecho Radar) monostatic antenna, to survey an area in the Coliseum valley.

A total of 243 adjacent profiles at the site of " $\mathrm{N}-\mathrm{E}$ foot of Palatino hill" were collected alternately in reversed and unreversed directions across the survey grids. The horizontal spacing between parallel profiles for both antennas at the site was $0.5 \mathrm{~m}$. Radar reflections along the transects were recorded in continuous acquisition mode across the ground at $80 \mathrm{scan} \mathrm{s}^{-1}$, horizontal stacking was set to 4 scans. Along each profile 
markers were spaced every $1 \mathrm{~m}$ to provide spatial reference. All radar reflections within the $95 \mathrm{~ns}, 105 \mathrm{~ns}, 113 \mathrm{~ns}$ and $150 \mathrm{~ns}$ (two-way-travel time) time windows were recorded digitally in the field as 8 and 16 bit data and 512 samples per radar scans.

A total of 63 adjacent profiles at the site "Coliseum valley" were collected alternately in reversed and un-reversed directions across the survey grids. The horizontal spacing between parallel profiles at the site was also $0.5 \mathrm{~m}$ and at a collection rate of 80 scan/s; horizontal stacking was set to 4 scans for both antennas. Along each profile markers were spaced every $1 \mathrm{~m}$ to provide spatial reference. All radar reflections within the $100 \mathrm{~ns}$ and 150 ns (two-way-travel time) time window were recorded digitally in the field as 8 and 16 bit data and 512 samples per radar scans.

The data were subsequently processed using standard twodimensional processing techniques employing the GPR-SLICE v7.0 Ground Penetrating Radar Imaging Software (Goodman, 2011, 2013). The basic radargram signal processing steps included: (i) header editing for inserting the geometrical acquisition information; (ii) DC drift removal; (iii) manual regaining to adjust the acquisition gain function and enhance the visibility of deeper anomalies; (iv) data resampling, (v) frequency analysis; (vi) band pass filtering, (vii) customized background removal filter to attenuate the horizontal banding and (viii) Kirckof migration using a constant average velocity [4].

With the aim of obtaining a planimetric vision of all possible anomalous bodies the time-slice representation technique was applied using all field profiles (Goodman and Piro, 2013). Time-slices are calculated by creating 2-D horizontal contour maps of the wave energy from a specified time value across parallel profiles, employing GPR-Slice software. Time slice data sets were generated by spatially averaging the squared wave amplitudes of radar reflections in the horizontal as well as the vertical, Figure 1.

Background filtering was used to remove line noises that were found to exist in the raw unprocessed images. Using these spatial averages, interpolated and solid 3D volumes of

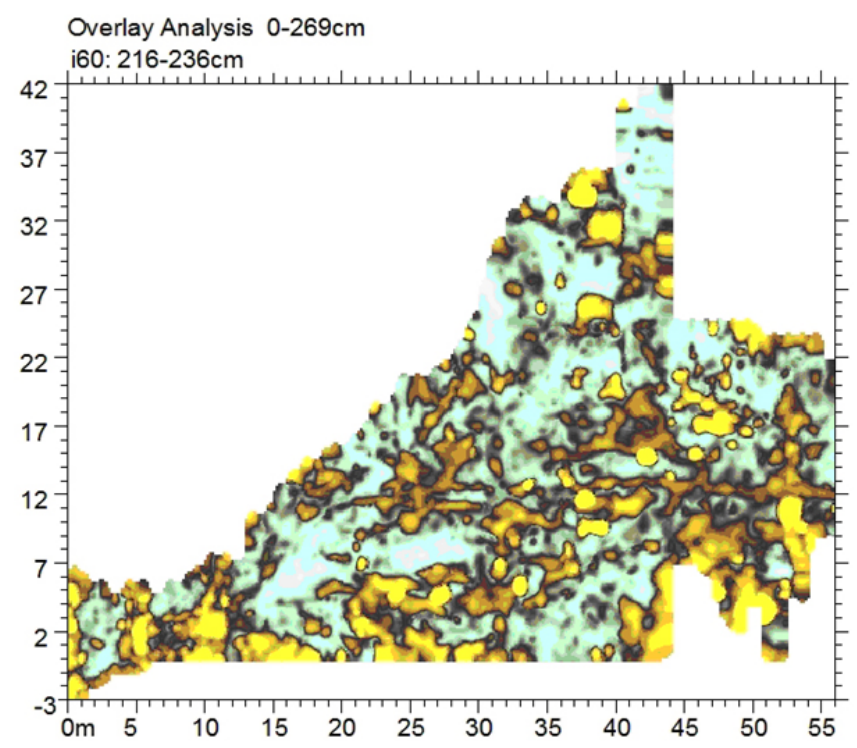

Figure 1. Overlay analysis was applied to the dataset using a map that collected the relative-strongest-reflectors recorded on 24 individual time slices from the ground surface to a depth $239 \mathrm{~cm}$. The time slice maps near the surface were underweighted using data transforms to deemphasize the ground surface reflections. reflection amplitudes were generated. Using spatially binned and interpolated volumes of radar data show better continuity in mapping subsurface reflections, which are more useful and provide archaeologist an interpretable form of data presentation, then using simple raw or filtered radargrams as volume elements, Figures 1, 2 and 3.

A nominal microwave velocity of about $10 \mathrm{~cm} / \mathrm{ns}$ was determined from fitting hyperbolas to the raw field data. This was used in estimating a penetration depth from the GPR survey.

During the systematic archaeological investigations made subsequent to the geophysical surveys, from 2001 to 2011, between the N-E foot of Palatino Hill and the Colosseum Valley and nearest Elagabalo's Thermae, a sequence of complex buildings, related to the Roman period between the late Republican and Severo's age were discovered [5], [6]. As an example, the structures indicated with USM5008 (Flavian era) and USM5045 (Nero's era) (Figure 3) are foundations made in cementitious, $0.90 \mathrm{~m}$ wide and $12 \mathrm{~m}$ long. In the area these reflections individuated at depth $0.60 \mathrm{~m}$, Figure 2, continue till

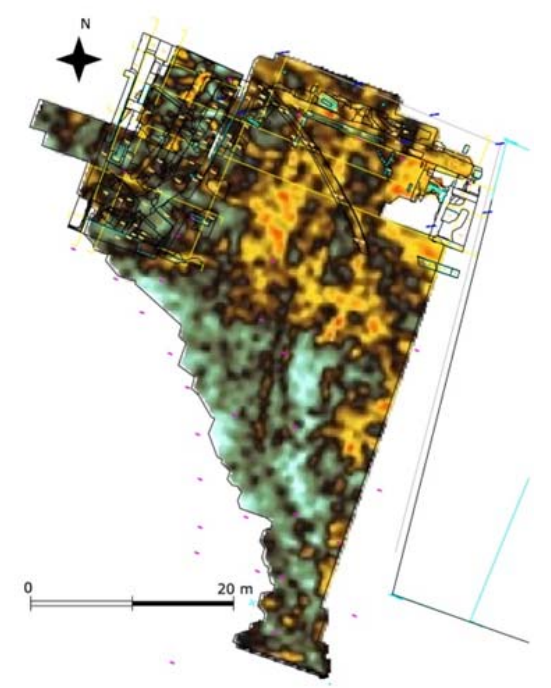

Figure 2. GPR time slice at a depth of $0.60 \mathrm{~m}$ indicates the presence of many reflections due to remains of archaeological structures that have been found during the first excavations of 2001-2004.

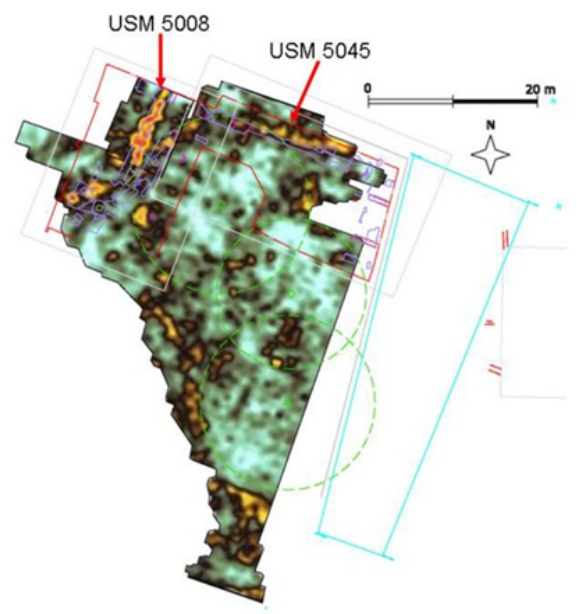

Figure 3. GPR time slice at a depth of $2.40 \mathrm{~m}$ indicates two main walls (USM5008 and USM5045) which have been found after the archaeological excavation (violet contour on the map). 
the depth of $2.40 \mathrm{~m}$, Figure 3. The results obtained with the GPR surveys have allowed the location of three rooms with rectangular shape, that are clearly visible at $0.60 \mathrm{~m}$ depth, Figure 2 , while in the deeper slices the corresponding images are not so clear. This is due to the combination of many reflected signals due to the presence inside the rooms of the collapse of the adjacent structures. From the excavations the found oldest building is a domus of the late Republican period located in front of a line of buildings called tabernae which were used for shops and living quarters. This corridor of buildings connected the Colosseum Valley and the Roman Forum. The fire-raising of 64 A.C., signed the destruction of these buildings and the development of Nero's urbanism. The archaeological excavations have located a portion of the foundation of a portico, and a portion of a sewage system with $\mathrm{S}-\mathrm{N}$ direction and a foundation with $\mathrm{E}$ shape, which defines and closes Elagabalo's Thermae, [6], [7], Figures 3 and 4.

\subsection{St. John Lateran Basilica}

The Basilica of S. Giovanni in Laterano (St. John Lateran) is the Pope's Cathedral and the first public building constructed for Christian worship. Alongside it lies the first Baptistery in western Christendom. The complex has been the focus of sundry excavations since the $1730 \mathrm{~s}$. These have revealed traces of the earliest phases of both buildings, along with parts of the Castra Nova of the Imperial Horseguard, a bath complex and palatial housing. Interpretation of these excavations is, however, difficult and most are either undocumented or only partially recorded.

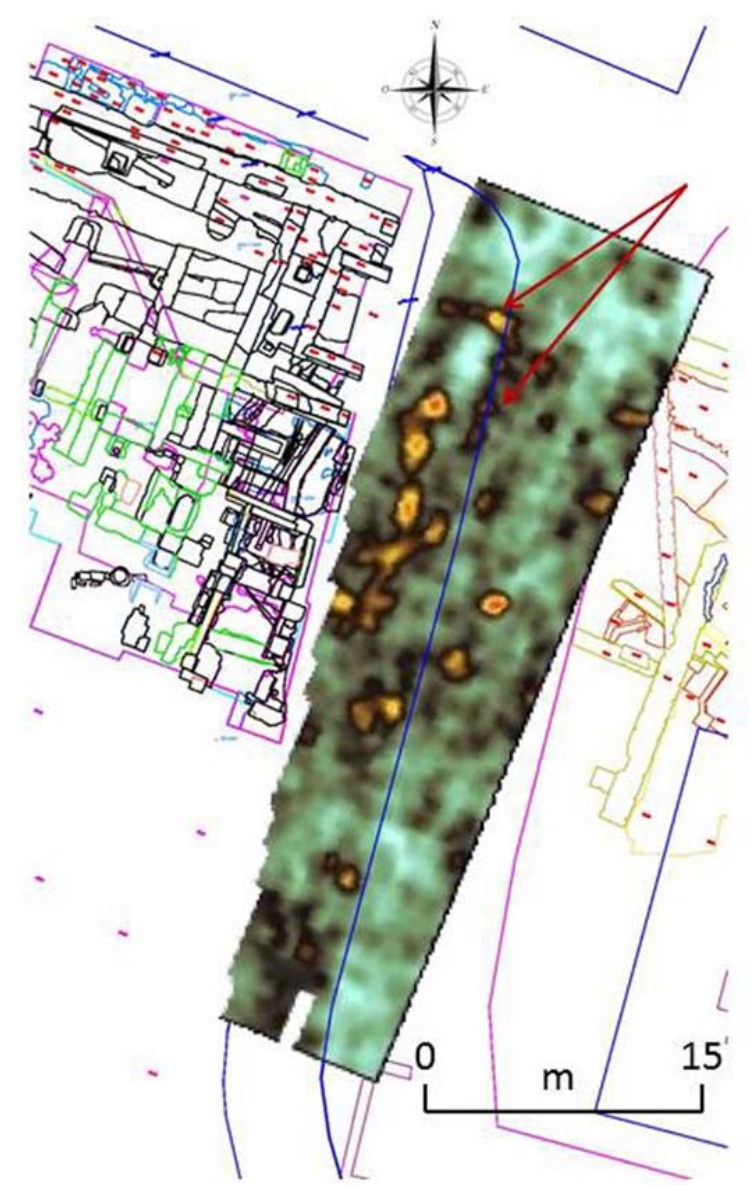

Figure 4. Coliseum Valley, Rome. Survey 2008. GPR time-slice at the depth of $2.70 \mathrm{~m}$. The arrows indicate the remains of the front of a temple, partially found in the excavated area.
This project is undertaking an intensive scientific survey of the entire structure to integrate information from standing buildings, excavated structures and sub-surface features through the collaboration of Newcastle University (UK), Florence University (Italy), Musei Vaticani and Institute for Technologies Applied to Cultural Heritage (ITABC-CNR, Italy).

The Lateran project is investigating the entire complex to integrate information from standing buildings, excavated structures and sub-surface features. It seeks to understand the stratigraphic, spatial and functional relationships of the different elements underlying the modern complex [8].

The GPR surveys provide information on the spatial context and identification of phasing of subsurface features while the laser scanning provides a spatially accurate, detailed representation of the many materials, textures and structures of the Lateran and archaeological remains [9].

During January and July 2012, a series of GPR surveys were conducted below the basilica, inside the archaeological area, and outside the basilica, to demonstrate the potential of this method for this analysis and to locate the expected archaeological structures.

The aim of the GPR survey is to identify Roman and highmedieval age remains which could enhance understanding of the ancient topography and the urban evolution of the study area. The main goals of this survey are the following:

1. to determine the full plan of the Santa Croce oratory, built by Pope Ilaro ( $V$ century) and destroyed by Sixtus the Fifth; part of this building has been identified by Olof Brandt within the excavated area adjacent to the Baptistery.

2. to determine the full extent of the palatial housing found below the western part of the Basilica.

3. to determine the limits of Castra Nova Equiutum Singularium, the barracks of the imperial horse guards established by the emperor Septimius Severus.

4. to locate the remains of the buildings of the Lateran Patriarchy. These are known from renaissance plans but up until now it has not proven possible to locate them all on the ground.

For the measurements a GPR SIR3000 (GSSI), equipped with a $400 \mathrm{MHz}$ (high-frequency) (GSSI) bistatic antenna with constant offset and a $70 \mathrm{MHz}$ (low-frequency) (Subecho Radar) monostatic antenna were employed. Some signal processing and representation techniques have been used for data elaboration and interpretation. GPR surveys were performed, employing the indicated system to survey the selected areas outside the Basilica in the S. Giovanni in Laterano square and in front of the Basilica.

The horizontal spacing between parallel profiles at the site was $0.50 \mathrm{~m}$, employing the two antennas. Radar reflections along the transepts were recorded continuously, with different length, across the ground at $40 \mathrm{scans} / \mathrm{s}$; horizontal stacking was set to 3 scans.

In the area outside the Basilica a total of 777 adjacent profiles across the site were collected alternatively in forward and reverse directions employing the GSSI cart system equipped with odometer. All radar reflections within the $90 \mathrm{~ns}$ for $400 \mathrm{MHz}$ antenna and $195 \mathrm{~ns}$ for $70 \mathrm{MHz}$ antenna (twoway-travel) time window were recorded digitally in the field as 16 bit data and 512 samples per radar scan.

A nominal microwave velocity of about $8 \mathrm{~cm} / \mathrm{ns}$ was determined from fitting hyperbolas to the raw field data. This was used in estimating a penetration depth from the GPR survey. 
All the GPR data were processed in GPR-SLICE v7.0 Ground Penetrating Radar Imaging Software (Goodman, 2011, 2013). The basic radargram signal processing steps included: (i) post processing pulse regaining; (ii) DC drift removal; (iii) data resampling, (iv) band pass filtering, (v) migration and (vi) background filter.

With the aim of obtaining a planimetric vision of all possible anomalous bodies the time-slice representation technique was applied using all processed profiles [3], [9]. Time-slices are calculated by creating 2-D horizontal contour maps of the averaged absolute value of the wave amplitude from a specified time value across parallel profiles.

The squared amplitudes were averaged horizontally every $0.25 \mathrm{~m}$ along the reflection profiles $3 \mathrm{~ns}$ (for $400 \mathrm{MHz}$ antenna) and $6 \mathrm{~ns}$ (for $70 \mathrm{MHz}$ antenna) time windows (with a $10 \%$ overlapping of each slice). The resampled amplitudes were gridded using the inverse distance algorithm with a search radius of $0.75 \mathrm{~m}$, Figures 5 and 6 .

In Figures 5 and 6 the time-slices (at the estimated depth of $1.40 \mathrm{~m}$ in front of the basilica and $2.0-2.40 \mathrm{~m}$ in the NW of the basilica) for the investigated area are shown. On this map the individuated anomalies are clearly visible. The GPR slice in Figure 5 (left) is characterised by structures with different dimensions and shapes. At the estimated depth, the squared structure with L-shape and surface of about $130 \mathrm{~m}^{2}$ is visible. Close to this structure, there is a rectangular body characterised on the left edge by a sequence of small squared rooms with

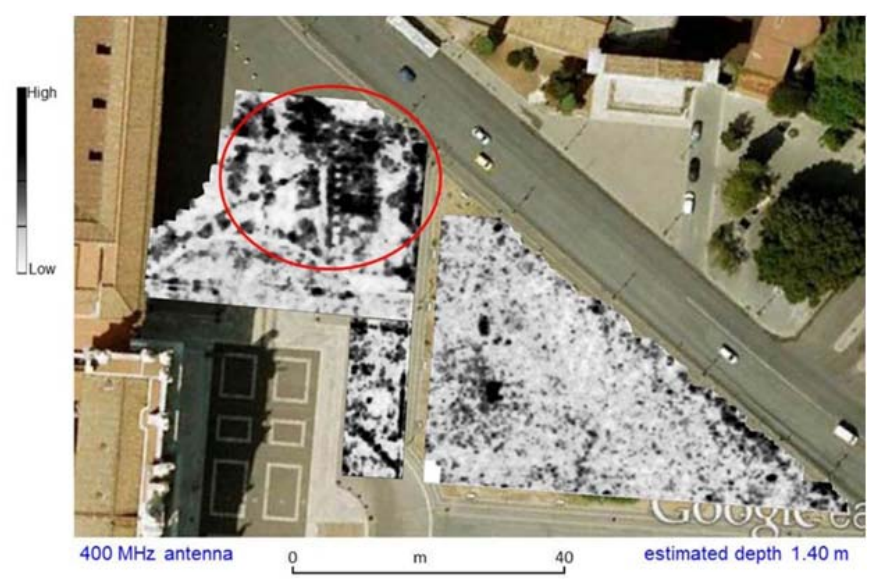

Figure 5. St. John Lateran square. GPR time slices in the time window 58-61 ns twt (estimated depth $1.4 \mathrm{~m}$ ) for the $400 \mathrm{MHz}$ antenna.
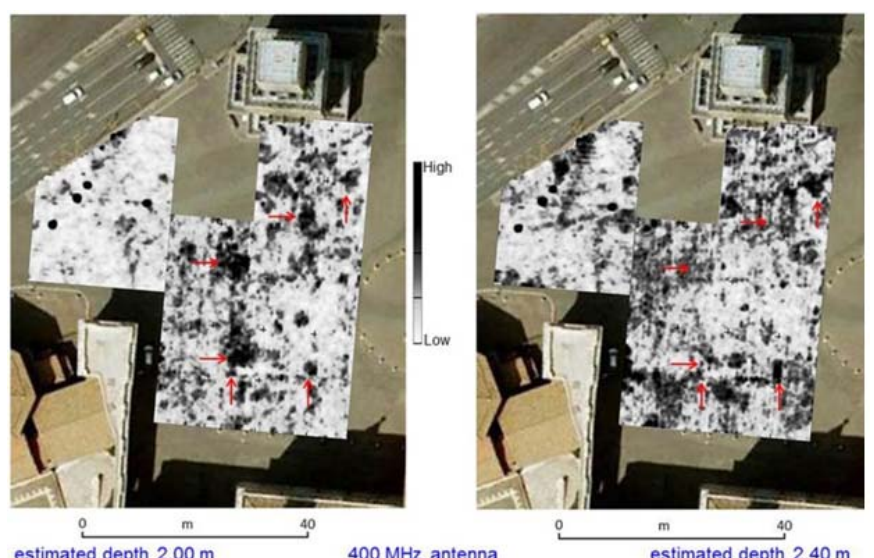

Figure 6. St. John Lateran square. GPR time slices at the estimated depth 2.0 and $2.4 \mathrm{~m}$, for the $400 \mathrm{MHz}$ antenna. dimensions of $1.2 \times 1.2 \mathrm{~m}$. In front of these anomalies it is possible to recognize two semi-circular anomalies with a diameter of about $10 \mathrm{~m}$. These anomalies obtained in front of the basilica, Figure 5, can be related to the remains of the early Christian bishop's palace (high medieval period) [8].

\section{CONCLUSION}

The location, depth, size and vertical overlapping of the buried buildings were effectively estimated from nondestructive ground remote sensing with a ground penetrating radar system, together with information on the geomorphology and on the archaeology of the two sites. The employment, on the same area, of two different frequencies (high and low frequencies) makes possible the integration of the results along the time (depth) vertical scale. This is possible because the high frequency $(400 \mathrm{MHz})$ can detect small features till the depth of $4.5 \mathrm{~m}$ and the low frequency $(70 \mathrm{MHz})$ can penetrate deeper detecting biggest features as foundations (as the case of Palatine Hill).

The archaeological excavations made at Palatine Hill (by Prof. Clementina Panella - Sapienza University of Roma) during the last years, have confirmed the structures individuated with the GPR method. The results presented in this paper are only related to the first period of the project; new comparison and integration between the GPR images and the archaeological excavation of the last few years are part of the PRIN2012 project. The new surveys are planned to investigate the area between the Coliseum, the Costantino's Arc and the Via Sacra at Roman Forum.

Ground Penetrating Radar (GPR) survey at the St. John Lateran Basilica has produced significant and fruitful results. The use of two different antennae, as the case of Palatine Hill, has enabled to reach depths of up to $7 \mathrm{~m}$. The GPR images obtained in front of the basilica, Figure 5, are characterised by structures with shape similar to that expected medieval archaeological structures but with different orientation [8]. This result is in accordance with the orientation of the Castra and of Costantino's basilica, while it departs from the knowledge of ancient topography. The comparison between the results obtained with GPR surveys with the archaeological knowledge is still in progress.

\section{ACKNOWLEDGEMENT}

The authors are very grateful to Daniele Verrecchia (ITABC) for his fruitful collaboration during the surveys, the team of Prof. C. Panella for the support inside the Palatine Project, the team of Newcastle University for the topographic support and Authorities of Musei Vaticani and St. John Lateran Basilica for their help during the survey.

\section{REFERENCES}

[1] S. Campana and S. Piro, Seeing the Unseen. Geophysics and Landscape Archaeology, CRC Press, Taylor \& Francis Group, Oxon UK, (2009), ISBN 978-0-415-44721-8.

[2] I. Trinks, P. Karlsson, A. Biwall and A. Hinterlaitner, Mapping the urban subsoil using ground penetrating radar - challenges and potentials for archaeological prospection, ArchaeoScience, revue d'archeometrié, 2009, suppl. 33, pp. 237-240.

[3] D. Goodman and S. Piro, GPR Remote sensing in Archaeology, 2013, Springer (Ed), ISBN 978-3-642-31856-6, ISBN 978-3-64231857-3 (eBook), DOI 10.1007/978-3-642-31857-3. Springer, Berlin, (Germany). 
[4] S. Piro S. and D. Goodman, Integrated GPR data processing for archaeological surveys in urban area. The case of Forum (Roma, Italy), 2008, 12th International Conference on Ground Penetrating Radar, June 16-19, 2008, Birmingham, UK. Proceedings Extanded Abstract Volume.

[5] S. Piro and C. Panella, Geophysical and Archaeological Investigations on the N-E foot of Palatino Hill (Rome, Italy), 2005, Proceedings of $6^{\text {th }}$ International Conference on Archaeological Prospection. Ed. Piro S., (ISBN 88-902028-0-7), pp 253-257, CNR, Rome.

[6] C. Panella, S. Piro, E. Brienza and S. Zeggio, Indagini geofisiche ed archeologiche in area urbana. Il caso delle Pendici orientali del Palatino (Foro Romano, Roma), 2008, in Atti del Workshop
Geofisica per l'Archeologia. Possibilità e Limiti, (Cistec, ed., Roma), pp $117-124$.

[7] C. Panella, Scavare nel centro di Roma. Storie uomini paesaggi, 2013, Edizioni Quasar, Roma.

[8] I. Haynes, P. Liverani, I. Peverett, S. Piro, G. Spinola, Progetto Laterano: primi risultati. In Rendiconti - Atti della Pontificia Accademia Romana di Archeologia (Serie III), Vol. LXXXVI, AA 2013-2014, 2014, pp 125-144, ISSN 1019-9500.

[9] V. Gaffney, S. Piro, I. Haynes, M. Watters, S. Wilkes, M. Lobb., D. Zamuner, Three-Tier Visualization of San Giovanni in Laterano, Rome, Italy, 2008, 12th International Conference on Ground Penetrating Radar, June 16-19, 2008, Birmingham, UK. Proceedings Extanded Abstract Volume. 